\title{
PSYCHE.
}

ORGAN OF THE CAMBRIDGE ENTOMOLOGICAL CLUB EDITED BY GEORGE DIMMOCK AND B. PICKMAN MANN.

Vol. II.] Cambridge, Mass., March, 1879. [No. 59.

\section{Geographical Distribution of North American Coleoptera.}

SECOND ANNUAL ADDRESS OF THE PRESIDENT.

Last year your president gave a sketch of the various contributions to the life-histories of our insects during the preceding year. I shall speak only of the geographical distribution of the Coleoptera; my excuse must be a lack of sufficient time, and a want of familiarity with the other groups. Any conclusions derived from the study of the geographical distribution of Coleoptera will have more value than if derived from other groups, because of the great number of species of Coleoptera, and the fact that this group has been much more extensively collected and studied in our region than any other.

The increasing popularity of the theory of the continuity of organic life from the earliest geological ages to the present time has given a great impetus to the study of questions of distribution, while at the same time every new fact in regard to distribution is important as tending to confirm or throw doubt on the theory.

So long as every species was supposed to be due to a special creative act, questions of distribution were of very little interest. It was as easy to conceive of the creation of the same species in several places, at the same or different times, as to conceive of the creation of several species in the same place. As soon, however, as one is convinced that all the specimens of a species are related to each other by descent from a common ancestor, and that all the species of a genus are also so related, and that when found in widely separated localities they 
must necessarily have emigrated from their original birth-place, every fact of distribution becomes a link in the chain of evidence of the successive migrations and changes of the species.

An examination of the literature of the subject shows that the past ten or fifteen years have furnished the greater part of the data for tracing the geographical distribution of our Coleoptera ; and it is only within five or six years that many extensive local lists have been published, based on careful collecting for a considerable time. I have made out a list of papers containing facts bearing on the distribution of the Coleoptera of boreal America, published during the last eleven years. My list includes nearly every paper on Coleoptera published during this period, because nearly every paper gives the localities of one or more species, and as the number of such papers is very great, it will of course be impossible for me to notice each one separately. They may be grouped as follows :

$1^{\circ}$. Independent descriptions of new species.

$2^{\circ}$. Monographs or analytical tables of species.

$3^{\circ}$. Lists of species collected in particular regions.

Many of the papers published are of a mixed nature, but a few of the more important ones, belonging substantially to the third group, are as follows :

Dr. Horn (Trans. Amer. Entom. Soc., 1868, v. 2, p. 123128) gives a list of 180 species from southwestern Virginia.

J. Pettit (Can. Entom., 1869, v. 1, p. 106-107, v. 2, p. 7, $17-18$; 1870, v. 2, p. 53-54, 65-66, 84-86, 102-103, 117$118,131-133,151 ; 1871$, v. 3 , p. 105-107 ; 1872, v. 4, p. 12-14) gives a list of 1143 species, of which 383 are indicated as new to the Canadian fauna. In Can. Entom., 1872, v. 4, p. $98-99$, he adds 65 species.

Dr. LeConte (Annals and Mag. Nat. Hist., 1869, s. 4, v. 4, p. 369-385) gives a list of 188 species collected in Vancouver's Island, with remarks on the wide distribution of some of the species; 17 species were not before known to occur so far west and 14 others not so far north.

S. V. Summers (Can. Entom., 1873, v. 5, p. 132-134, 145$147,168-170,190-192 ; 1874$, v. 6 , p. 52-55) enumerates, to the end of the Colydiidae, 595 species from St. Louis co., Mo. 
The same author (Bull. Buffalo Soc. Nat. Sci., 1874, v. 1, p. 78-99) enumerates 904 species from the region of Lake Pontchartrain, La., with remarks.

S. Henshaw (Psyche, 1874, v. 1, p. 17-18, 22-23) enumerates 135 species collected at Cliftondale, Mass., 12 June 1873.

E. P. Austin (Proc. Bost. Soc. Nat. Hist., 1874, v. 16, p. 265-272) gives a list of 232 species from Mt. Washington, N. H.

Dr. Horn (Trans. Amer. Entom. Soc., 1876, v. 5, p. 198201) enumerates 23 species from Guadalupe Island, with mention of the other known localities of the species.

J. D. Putnam (Proc. Davenport Acad. Nat. Sci., 1876, v. 1, p. 169-207) enumerates 226 species from near Davenport, Iowa; 37 from Monticello, Iowa; 19 from near Frederick, Iowa; 252 from the Rocky Mts. of Colorado ; 109 from northwestern Wyoming; 55 from Mt. Nebo alpine region, Utah (2100 to 3000 metres); 39 from a salt mud-flat near Utah Lake; 112 from the sage-brush region near Spring Lake Villa, Utah (1200 to 1800 metres).

Prof. Snow (Trans. Kans. Acad. Sci., 1877, v. 5, p. 15-20) enumerates 304 species from Colorado.

E. A. Popenoe (Trans. Kans. Acad. Sci., 1877, v. 5, p. 2140) enumerates about 1200 species from Kansas, with remarks.

By far the most important contributions to this subject which have recently been made are the work of two members of our club, who have given the results of several years' labor, in two papers published the past season. "The Coleoptera of Florida" by E. A. Schwarz, (Proc. Amer. Philos. Soc., 1878, v. 17, p. 353-472) contains remarks upon the nature of the region collected in ; descriptions, by E. A. Schwarz, of 34 new species, with a table of the species of Cyclonotum; descriptions of 141 new species by Dr. LeConte, of which 42 species are extra-limital, five species are noted for the first time as belonging to the fauna of the United States, 5 new genera are described and tables of the species of many genera are given; a list, by E. A. Schwarz, of 1457 species with localities, notes on comparative frequency, and other notes, and remarks by Dr. LeConte upon the distribution of species, accompanied by lists of the species of restricted range common to Florida and one 
or more adjacent regions. " The Coleoptera of Michigan," by H. G. Hubbard and E. A. Schwarz, (Proc. Amer. Philos. Soc., 1878, v. 17, p. 593-666, 669) contains descriptions of 63 new species by Dr. LeConte, with remarks on several other species, among which are four new to the American fauna, descriptions of three new genera, and tables of the species of several genera; descriptions, by Dr. Horn, of seven new species, with tables of the species of Mycetophagidae and Orchestes ; a list by Hubbard and Schwarz of 1246 species of Coleoptera found in the Lake Superior region, besides mention of the occurrence of many unnamed species in various groups; a list of 1787 species from the lower peninsula of Michigan; finally, a description of the larva of Micromalthus debilis, by H. G. Hubbard, with a plate figuring larva, imago and details of structure. Of the new species described 14 do not belong to the fauna of Michigan.

The various government surveys have also contributed considerable material towards a fauna of the great interior region of the continent. This is contained in the publications of the respective surveys as follows:

The Annual reports of the Geol. and Geog. Surv, of the Terr. under charge of Dr. Hayden, contain the following papers : by Dr. Horn (1872, rept. 2, p. 469-470) list of 123 species from Colorado and eastern New Mexico; (1872, rept. 5 , p. 382-392) list of 822 species from various regions, with remarks on the variation of certain species of extended geographical range; (1873, rept. 6, p. 717) list of 39 species from Yellowstone Lake, Teton Basin and Snake River ; (1877, rept. 9, p. 811-815) list of 146 species from Colorado and Utah; by Lieut. Carpenter (1874, rept. 7, p. 539-542) list of 16 species from the alpine region of Colorado: by Henry Ulke (1874, rept. 7, p. 567-571) list of 163 species from Colorado.

The Bulletin of the same survey contains the following papers : by P. R. Uhler (1877, v. 3, p. 770-779) list of 95 species from the western territories, with remarks; by Dr. LeConte (1878, v. 4, p. 447-480) list of 221 species from the alpine regions of the Rocky Mts., with remarks upon the altitudes at which they occur and upon geographical distribution, list of 30 species peculiar to the Rocky Mountain region, list of 154 species from Atalanta, Idaho (altitude 2340 metres). 
The Annual report upon the Geog. Surv. west of the 100th Meridian . . . by Lieut. Wheeler, contains the following papers : by H. Ulke (1875, p. 809-827) list of 389 species collected in several western states and territories, with localities; by Dr. LeConte $(1876$, p. 296-300) list of 75 species from southern California and 224 species from northern Colorado and northern New Mexico.

It may not be amiss also to note the publication of such lists of Coleoptera for sale as have indications of the localities; these are the earlier and smaller lists published by the Philadelphia Agency in 1874, and G. W. Belfrage's list of 471 Texan species in Psyche Advertiser for December 1876.

The preceding lists, from their extent or the interest attached to the localities, seemed to demand special notice, and the foregoing sketch shows that much progress has been made in collecting data for solving the problem of the present distribution of North American Coleoptera. The published lists, however, are far from representing the whole progress in that direction, and I will briefly notice some of the principal collections known to me which are capable of adding materially to our stock of knowledge, and which I trust will be used for that purpose in the near future.

Mr. Henry Ulke has collected for many years in the vicinity of Washington, D. C., and can give a nearly complete catalogue of the Coleoptera of that region.

Mr. Samuel Auxer has made a collection in the vicinity of Lancaster, Pa., which will give a good idea of the fauna of that section.

Good materials for a representation of the fauna of Texas exist in the collections of Messrs. Belfrage, Boll, and others.

The extensive collections made by Mr. G. R. Crotch, in California and British Columbia, would have contributed greatly to our knowledge of the distribution of the species of the $\mathrm{Pa}$ cific coast, as all the specimens had the localities carefully marked, if only a set had been kept together for investigation.

Mr. A. S. Fuller has accumulated, during the past few years, an immense collection from all parts of the country, which will doubtless furnish much information in this regard. 
The collections made by Mr. H. K. Morrison in Georgia and North Carolina in 1876, in Colorado in 1877, and in the Sierras during the past year, would be of great value, if a set of the specimens was kept together and sufficient pains were taken to separate species which are superficially alike.

The numerous collectors in New York and Brooklyn have done much also towards working up their local fauna and have begun to publish lists.

Several industrious collectors in Buffalo, N. Y. have done good work in this direction.

We may hope that the labors of Messrs. Hubbard and Schwarz are by no means completed. I have recently examined a collection of over 700 species taken by Mr. Schwarz, in Colorado, in a few weeks' collecting during the past season, and as this consisted only of the duplicates of the collection, there must be at least 1000 species in all.

Much has been done, though little published, towards working up the fauna of New England. The collections of Mr. G. Dimmock and others, in the Connecticut Valley, will give a good idea of the fauna of that section, which is very different from that of the eastern part of the state. Mr. F. Blanchard has made a collection in the vicinity of Lowell, Mass., which is probably the most complete local collection in New England.

For Boston and vicinity, the collections of the various members of the Club will furnish the basis for a pretty complete list, as soon as some one will undertake to prepare it.

Since the publication of ny list of Mt. Washington Coleoptera, materials have been gathered for a more full list of the species of that region.

Mr. S. Henshaw has been, for some time, collecting data for a complete list of New England species.

The materials already collected suggest many interesting questions in regard to the migrations of species, and concerning the former distribution of land and water on this continent. Some of these questions have already been noticed by Dr. LeConte and others, but it is evident that such problems are only beginning to be studied, and that when collections increase, and, particularly, when the great interior of the continent is as 
carefully explored as have been a few localities on each shore, numerous cases of remarkable distribution of species will be discovered, fully as interesting as any which have been already noticed.

Several interesting questions suggest themselves in regard to the Cicindelidae. Cicindela puritana, C. macra and C.cuprascens are no doubt comparatively recent forms of a formerly single species. C. puritana, having apparently become isolated at an early date, is now confined to the Connecticut Valley, and is in several respects intermediate between the other two species, which have a wide distribution in the western and southwestern states. C. macra and C. cuprascens probably occur together in many localities. C. macra is the most abundant and widespread form, and seems to have a tendency to separate into races, a tendency not yet noticed in $C$. cuprascens, and not to be expected in C.puritana, on account of its limited range.

In tracing out variations of species, it is of course important to pay attention to all variations which tend to become permanent, in other words to study the formation of races, which is, of course, the first step in the formation of new species. I cannot close this essay without entering a protest against a tendency, which has sprung up recently, of ignoring these variations and of regarding as synonyms the names under which they have been described, when in reality they are varieties, in many cases quite permanent, which are from separate regions and tend very little to run into each other. $\quad E$. P. Austin.

\section{BIBLIOGRAPHICAL RECORD.}

(Continued from page 216.)

The date of publication, here given in brackets [ ], marks the time at which the work was received by the Editor, unless an earlier date of publication is known to him. An asterisk * before a title is the Recorder's certificate of accuracy of quotation. Corrections of errors and notices of omissions are solicited. - B. Pickman Mann.

Nos. 1093 to 1135 are from Can. Entom., v. 8.

* 1093. A: R. Grote. New moths. p. 111-112. [June, 1876.]

Describes Botis submedialis and Eurymene rosaria (G. \& R.) from Canada, Hydrocampa ekthlipsis from N. Y. and Canada, Sisyrosea, S. nasoni 

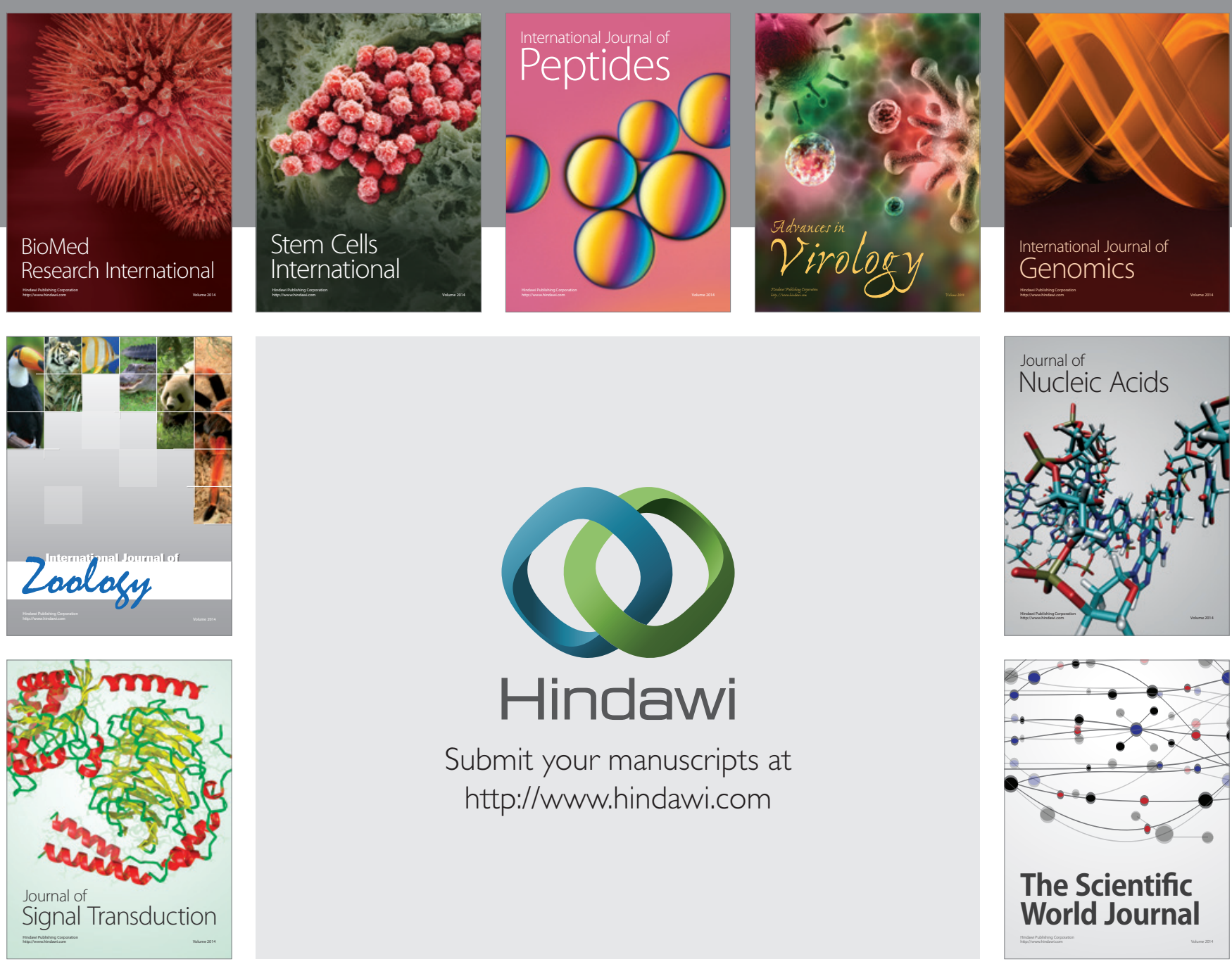

Submit your manuscripts at

http://www.hindawi.com
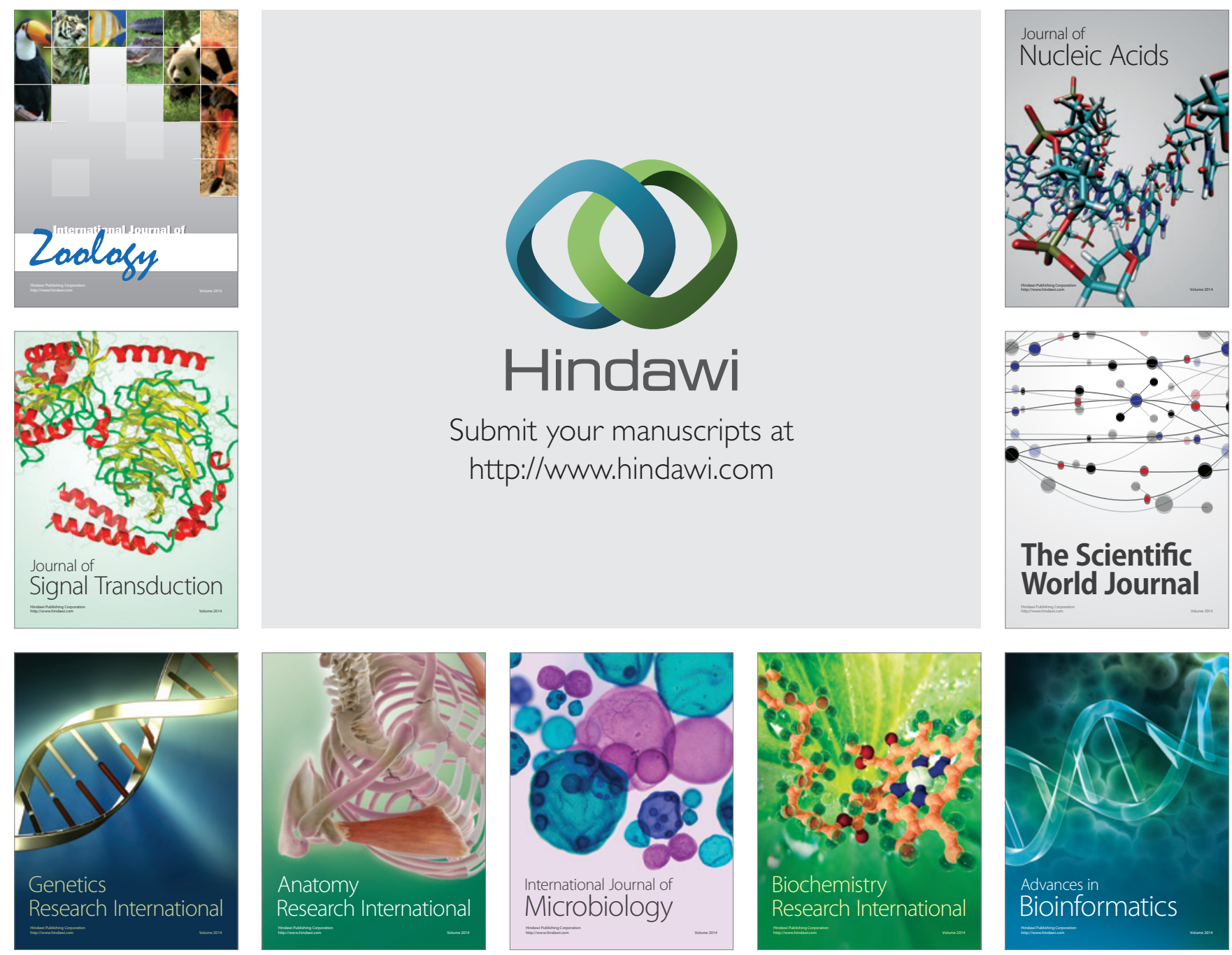

The Scientific World Journal
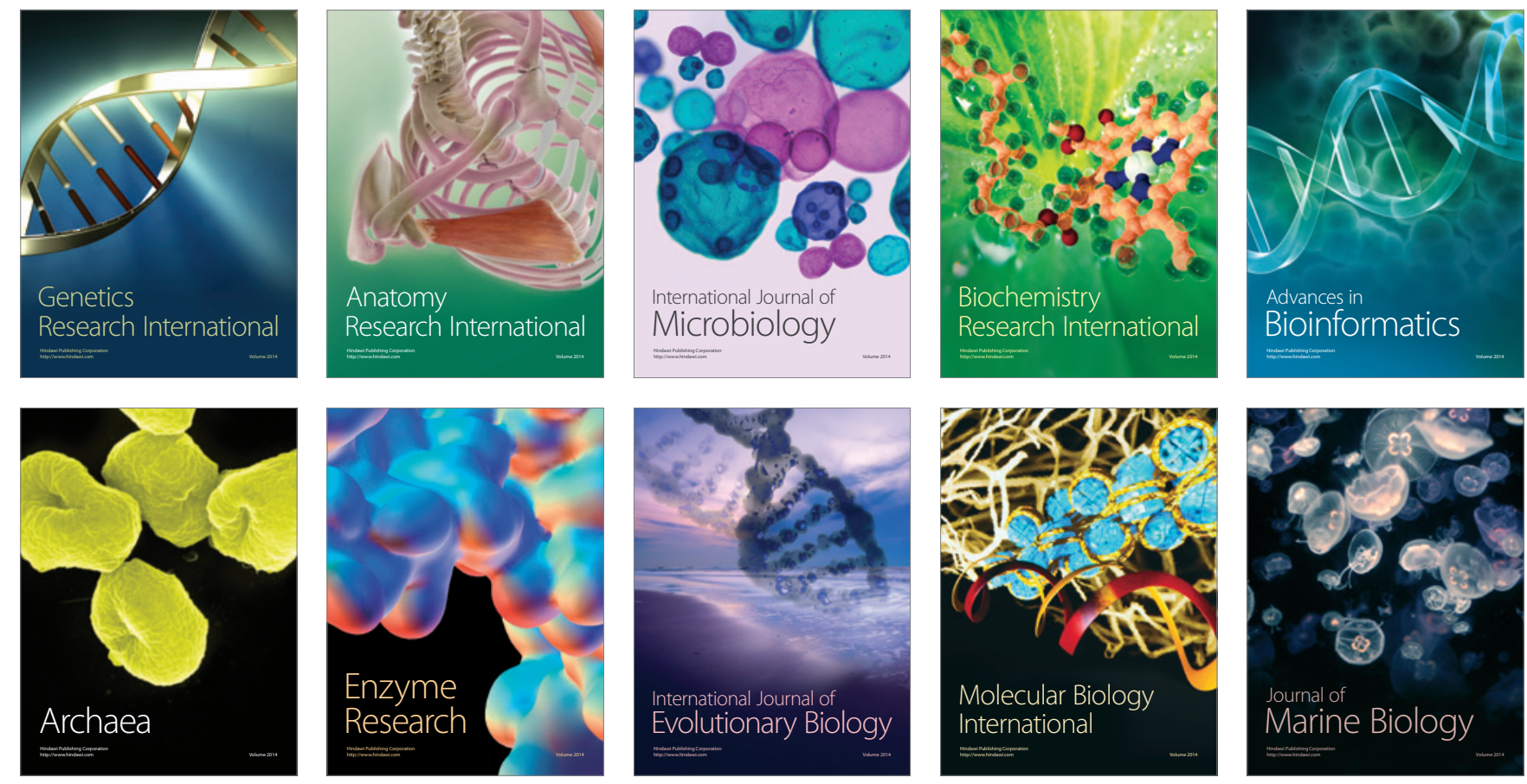